\title{
ANALISIS KEBIJAKAN INTRODUKSI SPESIES IKAN ASING DI PERAIRAN UMUM DARATAN PROVINSI ACEH
}

\author{
Z. A. Muchlisin \\ Jurusan Budidaya Perairan, Koordinatorat Kelautan dan Perikanan, Universitas Syiah Kuala, \\ Banda Aceh 23111; \\ Tsunami and Disaster Mitigation Research Center (TDMRC), Universitas Syiah Kuala, Banda Aceh \\ Email:muchlisinza@yahoo.com
}

Diterima 1 September 2011 - Disetujui 11 Desember 2011

\begin{abstract}
ABSTRAK
Provinsi Aceh memiliki potensi perikanan perairan umum daratan yang besar dengan berbagai spesies lokal. Potensi ini belum sepenuhnya dimanfaatkan baik untuk perikanan tangkap maupun budidaya. Di sisi lain, tekanan terhadap perairan umum daratan semakin meningkat terutama disebabkan oleh kerusakan lingkungan, pencemaran, pemanasan global dan introduksi spesies ikan asing yang mengancam komunitas ikan lokal. Introduksi spesies ikan asing menjadi isu penting, baik di tataran global maupun lokal. Kajian ini bertujuan untuk menganalisis dan mengadvokasi awal kebijakan introduksi spesies ikan asing di Provinsi Aceh. Untuk memberikan gambaran yang lebih jelas, kajian ini menggunakan studi kasus introduksi spesies ikan asing di Danau Laut Tawar. Kajian ini menggunakan metode analisis deskriptif-eksploratif dan studi literatur sebagai basis kebijakan introduksi spesies ikan asing yang perlu mendapatkan perhatian. Hasil kajian menunjukkan sebanyak sembilan spesies ikan asing telah ada diperairan Aceh. Dari jumlah tersebut, tujuh spesies diantaranya telah hadir di Danau Laut Tawar. Saat ini Pemerintah Provinsi Aceh belum memiliki kebijakan untuk mengatur introduksi spesies ikan asing ke perairan Aceh. Hal ini dapat menyebabkan ancaman terhadap spesies ikan lokal. Karena itu kebijakan berupa peraturan daerah yang mengatur hal tersebut sangat diperlukan.
\end{abstract}

Kata Kunci: endemik, konservasi, depik dan Danau Laut Tawar

\section{Abstract: Policy Analysis of Introducing Alien Species of Fish in Inland Waters of Aceh Province. By: Z. A. Muchlisin}

Aceh Province has abundance of inland fishery resources with various indigenous species. These resources are still underutilized both for aquaculture or capture fisheries. On the other hand, environmental pressures and threats to these resources are emerging due to ecological devastation, pollution, introduced alien species and global warming. Introduction of alien species of fish become a popular issue in local or global contexts. The objective of this research was to analyze and initiate advocacy on introduction of alien fish species regulation in Aceh Province. This research used a case study in Lake Laut Tawar to give a comprehensive understanding on the topic. Descriptive-explorative analysis and literature review were used in the study, and the results of the study can be used to develop a better conservation strategy and policy to control introduced alien species in Aceh waters. This research results show there are at least nine introduced alien species of fish in Aceh waters. Seven of them were found in Lake Laut Tawar. Aceh Provincial Government has no regulation on introduction of alien species into Aceh waters. This condition could threaten the indigenous species of Aceh fishes. Therefore, the regulation of the management of introduced fish species is really needed.

Keywords: endemic, conservation, alien species, Lake Laut Tawar 


\section{PENDAHULUAN}

Industri perikanan tangkap dunia berkembang dengan pesat dari kurun 1960 sampai 1970an, dalam masa tersebut perikanan tangkap tumbuh sebesar $6 \%$ per tahun, dan kemudian melambat mejadi 2,3\% per tahun selama priode 1970 sampai 1980an (FAO, 1998 dalam Ali, 2000). Pada priode 1994 sampai 1997, jumlah tangkapan dunia hanya naik $1.1 \%$, dilain pihak hasil tangkapan dari perairan umum naik secara drastis (15\%) dalam priode yang sama (FAO, 1997 dalam Zaidy, 2001).

Saat ini perikanan Aceh masih bertumpu pada perikanan tangkap khususnya perikanan tangkap laut dengan $295.370 \mathrm{~km}^{2}$ wilayah teroterial laut termasuk 238.807 zona ekonomi exclusif (ZEE) (Bappeda Provinsi Aceh, 2008); potensi tersebut masih dapat dikembangkan sampai dengan $60 \%$ dari potensi lestari yang diperhitungkan sebesar 272.707 ton per tahun. Disamping itu, Provinsi Aceh memiliki potensi sumberdaya perairan umum daratan yang cukup besar dengan luas sebesar 70.000 $\mathrm{Ha}$, termasuk 73 sungai-sungai besar, dua danau (Laut Tawar dan Aneak Laot) dan lahan gambut (misalnya, Rawa Singkil dan Rawa Tripa), namun potensi tersebut belum dimanfaatkan secara optimal. Hasil penelitian mencatat bahwa sekurang-kurangnya ada 114 spesies ikan air tawar dan payau hidup di perairan tawar Nanggrue Aceh Darussalam (Muchlisin dan Siti-Azizah, 2009), angka ini diperkirakan masih jauh dibawah jumlah spesies ikan yang ada karena masih banyak sungai, rawa-rawa dan danau yang belum di 'explorasi'; bahkan dari jumlah tersebut, 15 species diantaranya memiliki nilai ekonomi tinggi, antara lain: Anguilla bicolor (Ileah), Anguilla mamormata (Ileah), Chanos chanos (muloh, brackishwater), Channa striata (bacei), Channa lucius (bujok), Clarias batrachus (sengko/mut), Clarias teijsmanni (semu), Clarias niefhofii (semu), Epinephelus tauvina (geurape muara, brackishwater), Neolissochilus spp (pedih/jurong), Rasbora tawarensis (depik), Tor soro (jurong), Tor tambra (Keureling), dan Tor tambroides (keureling). Namun sayangnya keberadaan ikan-ikan tersebut kini dalam keadaan terancam oleh berbagai faktor, diantaranya adalah kerusakan lingkungan, pencemaran, teknik penangkapan yang tidak ramah lingkungan, perubahan iklim global dan introduksi spesies ikan asing. Introduksi ikan asing tersebut adalah sebagai konsekuensi implementasi kebijakan introduksi spesies ikan baik disengaja ataupun tidak disengaja untuk tujuan diversifikasi jenis ikan budidaya, pengontrolan vektor penyakit, ataupun untuk tujuan hobbi (ikan hias). Introduksi spesies ikan asing untuk tujuan peningkatan produksi perikanan mungkin menguntung secara ekonomi dalam jangka pendek, namun jika ini dilakukan secara tidak bertanggung jawab akan berdampak buruk bagi ikan-ikan asli setempat sehingga merugikan secara jangka panjang. Makalah ini bertujuan untuk menganalisis kebijakan introduksi spesies ikan asing khususnya di perairan Aceh dan dampak yang ditimbulkannya.

\section{METODOLOGI}

Metode deskriptif-eksploratif dan studi literatur digunakan dalam analisis ini. Studi literatur dilakukan terhadap penelitianpenelitian yang telah dilakukan berkaitan introduksi spesies asing dan dampaknya baik di tingkat nasional maupun global dan diperkaya dengan hasil-hasil penelitian terkini dari penulis sendiri dan wawancara dengan pihak-pihak terkait yang memahami permasalahan. Metode eksploratif dilakukan dengan melakukan survey lapangan di lima kawasan atau 17 lokasi sampling yang tersebar diseluruh kawasan dalam Provinsi Aceh (Tabel 1), dilakukan pada Januari sampai Juli 2007.

Penulis juga melakukan wawancara dengan lebih kurang 113 orang nelayan di Danau Laut Tawar untuk mengetahui hasil tangkapan tertinggi yang pernah terjadi dan masih diingat oleh setiap responden, untuk tujuan ini responden dipilih secara purposif agar dapat mewakili kelompok umur secara umum, yaitu nelayan tua (umur $>60$ tahun, nelayan paruh baya (umur antara 40-59 tahun) dan nelayan muda (umur $<40$ tahun). Sebagai pembanding juga dilakukan sampling langsung di danau untuk melihat kondisi terkini hasil 
tangkapan ikan khususnya ikan depik (Rasbora tawarensis). Data sekunder diperoleh dari beberapa instansi pemeritah dan swasta untuk mendukung analisis. Data-data yang diperoleh disajikan dalam tabel dan narasi dan selanjutnya dianalisis secara deskriptif.

\section{INTRODUKSI IKAN ASING DAN DAMPAKNYA}

Hasil survey di lima kawasan di Aceh berhasil mencatat sebanyak 114 spesies ikan air tawar hidup di perairan Aceh, dari jumlah tersebut 8 spesies diantaranya telah masuk dalam daftar merah IUCN (IUCN Red List), yaitu; Doryichthys heterosoma (cocuk geulinyung buya), Channa cyanospilos (jampak), Neolissochilus spp (pedih/jurong), Poropuntius tawarensis (kawan), Rasbora tawarensis (depik), Tor tambra (keureling), T. tambroides (keureling) and Tor soro (jurong), bahkan dua spesies dikategorikan sebagai critical endangered species (Depik, Rasbora tawarensis dan Kawan, Poropuntius tawarensis) keduanya endemik di Danau Laut Tawar, Aceh Tengah. Dari survey ini juga ditemukan ada sembilan spesies ikan asing (introduced species) di perairan Aceh yaitu Clarias gariepinus (lele dumbo), Cyprinus

Tabel 1. Lokasi Sampling Ikan dalam Lima Kawasan di Provinsi Aceh.

Table 1. Fish Sampling Locations in Five Regions of Aceh Province.

\begin{tabular}{|c|c|c|}
\hline $\begin{array}{c}\text { Wilayah/ } \\
\text { Region }\end{array}$ & Kabupaten/ District & Lokasi sampling/ Sampling site \\
\hline $\begin{array}{l}\text { Barat/ } \\
\text { Western }\end{array}$ & $\begin{array}{l}\text { Aceh Jaya, Aceh Barat } \\
\text { dan Nagan Raya }\end{array}$ & $\begin{array}{l}\text { (1) Sungai Lagean di Aceh Jaya/ Lagean River, Aceh } \\
\text { Jaya; (2) Sungai Meurebo/ Meurebo River, (3) Sungai } \\
\text { Woyla/ Woyla River dan/ and (4) Sungai Alue Pedeang } \\
\text { di Aceh Barat/ Alue Pedeang River, Aceh Barat; (5) } \\
\text { Areal persawahan dan saluran irigasi Desa Simpang, } \\
\text { Aceh Barat/ Paddy fields and irrigation canals of } \\
\text { Simpang Village, Aceh Barat; (6) Rawa Gambut Kuala } \\
\text { Tuha/ Peat swamp of Kuala Tuha dan/ and (7) Sungai } \\
\text { Nagan di Nagan Raya/ Nagan River in Nagan Raya }\end{array}$ \\
\hline $\begin{array}{l}\text { Selatan/ } \\
\text { Southern }\end{array}$ & $\begin{array}{l}\text { Aceh Selatan } \\
\text { (Ekosistim Leuser/ } \\
\text { Leuser Ecosystem) }\end{array}$ & $\begin{array}{l}\text { (8) Sungai Lembang di Aceh Selatan/ Lembang River } \\
\text { in Aceh Selatan }\end{array}$ \\
\hline $\begin{array}{l}\text { Tengah/ } \\
\text { Central }\end{array}$ & $\begin{array}{l}\text { Aceh Tengah dan } \\
\text { Aceh Tenggara }\end{array}$ & $\begin{array}{l}\text { (9) Sungai Alas (Ketambe) di Aceh Tenggara/ Alas } \\
\text { River (Ketambe), Aceh tenggara dan/ and (10) Danau } \\
\text { Laut Tawar di Aceh Tengah/ Lake Laut Tawar, Aceh } \\
\text { Tengah }\end{array}$ \\
\hline $\begin{array}{l}\text { Timur/ } \\
\text { Eastern }\end{array}$ & $\begin{array}{l}\text { Pidie, Bireun dan } \\
\text { Aceh Tamiang }\end{array}$ & $\begin{array}{l}\text { (11) Sungai Tamiang/ Langkat di Aceh Tamiang dan } \\
\text { Langkat/ Tamiang and Langkat River, Aceh Tamiang; } \\
\text { (12) Sungai Batee Iliek di Bireun/ Batee Iliek River, } \\
\text { Bireun; (13) Saluran air tambak Pante Radja di Pidie/ } \\
\text { Coastal pond canals in Pante Radja, Pidie }\end{array}$ \\
\hline $\begin{array}{l}\text { Utara/ } \\
\text { Northern }\end{array}$ & $\begin{array}{l}\text { Aceh Besar dan } \\
\text { Banda Aceh }\end{array}$ & $\begin{array}{l}\text { (14) Sungai Aceh/ Aceh River dan/ and (15) Sungai } \\
\text { Cut di Banda Aceh/ Cut River in Banda Aceh; (16) } \\
\text { Sungai Montala dan/ Montala River and (17) Areal } \\
\text { persawahan dan saluran irigasi di Sibreh, Aceh Besar/ } \\
\text { Paddy fields and irrigation canals of Sibreh, Aceh } \\
\text { Besar }\end{array}$ \\
\hline
\end{tabular}

Sumber : Muchlisin, 2010.

Source : Muchlisin, 2010. 
carpio (ikan mas), dua spesies tilapia, yaitu Oreochromis mossambicus (mujair) dan $O$. niloticus (nila), dua spesies ikan plati, yaitu Xiphophorus helleri, X. maculatus, Hiposarcus pardalis (sapu kaca), Poecillia spp (ikan seribu) and Ctenopharyngodon idella (grass carp atau ikan Cina). Jumlah tersebut tergolong tinggi, dan diyakini terus bertambah, seiring giatnya usaha-usaha untuk mendatangkan ikan asing oleh pihak-pihak tertentu dan tidak adanya kepedulian dari pihak terkait untuk membendungnya.

Tidak ada catatan pasti bila dan ikan jenis apa yang pertama kali diintroduksi ke perairan Aceh. Diprediksi jenis ikan yang pertama kali diintroduksi ke Aceh adalah mujair ( $O$. mossambicus), diintroduksi pertama kali ke Danau Laut Tawar antara tahun 1955-1957, oleh seorang nelayan yang bernama Raja Ilang (Pers. comm dengan ketua kelompok nelayan Danau Laut Tawar).

Di Indonesia, ikan mujair pertama kali ditemukan sekitar tahun 1936 atau 1939 (ada dua versi tahun pertama ditemukan) di muara Sungai Blitar, Jawa Timur oleh Bapak Moedjair, namun tidak diketahui siapa yang mengintroduksikannya, oleh karena itu ikan ini lebih dikenal dengan sebutan ikan mujair. Ikan mujair dan nila telah diintroduksi ke lebih 90 negara, 15 negara diantaranya telah melaporkan dampak negatifnya terhadap ekologi (Casal, 2006), dan bahkan ikan mujair dan ikan mas telah dilebel sebagai top 100 of the world's worst invasive alien species (GISP, 2004).

Terdapat pro dan kontra terhadap dampak introduksi spesies ikan asing, namun sebagian besar ilmuwan sepakat bahwa kegiatan ini berdampak buruk bagi lingkungan dan dunia perikanan secara umum dalam jangka panjang, dan masalah ini telah menjadi isu global (Sorensen dan Hoye, 2007). Secara umum, introduksi ikan asing ke suatu perairan menyebabkan populasi ikan asli setempat turun dan bahkan punah. (Saunders et al., 2002), hal ini disebabkan karena terjadinya pemangsaan terhadap ikan lokal (Nicola et al., 1996), kompetesi dalam mendapatkan makanan dan pemanfaatan habitat (Alcaraz and Garcia-Bethou, 2007), kegagalan untuk mendapatkan pasangan (Seehausen et al., 1997), meningkatkan peluang penyebaran patogen penyebab penyakit pada ikan bahkan manusia (FAO, 2005), terjadinya kawin silang yang tidak diharapkan dengan species lokal (Almodovar et al., 2006) yang menyebabkan hilangnya gen-gen pembawa sifat unggul, misalnya ketahanan terhadap penyakit.

Sebagai ilustrasi, introduksi ikan 'redbreast sunfish' (Lepomis auritus) ke beberapa danau di Italia telah menyebabkan populasi ikan asli setempat Alburnus alburnus berkurang drastis dan populasinya digantikan oleh ikan pendatang tersebut, dan introduksi ikan trout Salmo trutta ke perairan New Zealand juga menyebabkan populasi ikan endemic New Zealand grayling (Protoctes oxyrhynchus) turun drastis (Wargasasmita, 2002). Lebih lanjut Strecker (2006) melaporkan bahwa populasi ikan Cyprinodon sp and Gambusia sexradiata di Laguna Chichancanab, Mexico menurun tajam setelah terjadinya invasi ikan Astyanax fasciatus and Oreochromis (African cichlid), bahkan Cyprinodon simus yang hidup disana dilaporkan sangat sukar dijumpai dan prediksi telah pupus.

Suatu fenomena yang sangat terkenal yang terjadi di Danau Victoria dan Danau Kyoga yang terletak di bagian timur Afrika, peristiwa ini didokumentasi dengan baik dan menarik perhatian para saintis. Jumlah species dan kelimpahan ikan lokal menurun drastic setelah introduksi ikan nile perch (Lates niloticus) di kedua danau tersebut. Akibatnya sangat buruk, menyebabkan produksi perikanan di Nyanza Gulf, Kenya kolaps pada Tahun 1985. Seluruh nelayan menerima dampak buruk dari peristiwa ini akibat kehilangan mata pencaharian dan terpaksa dipindah dari teluk tersebut (Barlow and Lisle, 1987).

Dalam konteks Aceh, dampak introduksi ikan asing juga sudah dirasakan. Di Danau Laut Tawar (DLT) misalnya, populasi ikan Depik (Rasbora tawarensis) masih merupakan spesies yang dominan dalam era 70 - 80an (Pers. comm. dengan nelayan Aceh), namun saat ini ikan nila (O. niloticus) sudah mengambil 
alih dan mendominasi populasi ikan disana. Lebih lanjut di Desa Simpang, Kecamatan Kaway 16 Aceh Barat misalnya, masyarakat disana mengklaim kehadiran ikan lele dumbo (Clarias gariepinus) di perairan umum dan areal persawahan setempat telah menyebabkan populasi ikan lele lokal semakin berkurang. Namun sayangnya belum ada langkah-langkah konkrit untuk membatasi penyebarannya baik dari pemerintah maupun lembaga swadaya masyarakat yang konsen dalam bidang lingkungan, bahkan terkesan pemerintah tidak memahami persoalan.
Secara nasional jumlah ikan asing yang diintroduksi ke perairan Indonesia masih tergolong rendah, 19 spesies (Wargasasmita, 2002) bila dibandingkan dengan Malaysia, 26 spesies (Chong et al., 2010), Singapore 22 spesies (Tan and Koh-Siang, 2003), India 24 spesies (Kumar, 2000) dan Nepal 23 spesies (Gurung, 2005), namun masih lebih tinggi dibandingkan dengan Bangladesh, 15 spesies (Islam et al., 2003). Sejauh ini negara yang paling banyak mengintroduksi ikan asing adalah Yunani 66 spesies (Zenetos et al., 2009) dan Polandia 40 spesies (Nowak et al., 2008) (Tabel 2).

Tabel 2. Jumlah Ikan Introduksi Berdasarkan Negara.

Table 2. Total Number of Fish Species Introduced According to Countries and Sources.

\begin{tabular}{clll}
\hline No & Negara/ Country & $\begin{array}{c}\text { Jumlah ikan introduksi/ } \\
\text { Total Number of } \\
\text { Introduced fish }\end{array}$ & \multicolumn{1}{c}{ Sumber/ Sources } \\
\hline 1 & Yunani/ Greece & 66 spesies/ 66 species & Zenetos et al. (2009) \\
2 & Polandia/ Poland & 40 spesies/ 40 species & Nowak et al. (2008) \\
3 & Austria/ Austria & 27 spesies/ 27 species & Rabitsch and Essl, (2006) \\
4 & Israel/ Israel & 27 spesies/ 27 Species & Roll et al. (2007) \\
5 & Malaysia/ Malaysia & 26 spesies/ 26 species & Chong et al. (2010) \\
6 & Spanyol/ Spain & 25 spesies/ 25 species & Ribeiro et al. (2008) \\
7 & India/ India & 24 spesies/ 24 species & Kumar, (2000) \\
8 & Nepal/ India & 23 spesies/ 23 species & Gurung, (2005) \\
9 & Singapura/ Singapore & 22 spesies/ 22 species & Tan and Koh-Siang, (2003) \\
10 & Indonesia/ Indonesia & 19 spesies/ 19 species & Wargasasmita, (2002) \\
11 & Bangladesh/ Bangladesh & 15 spesies/ 15 species & Islam et al. (2003) \\
\hline
\end{tabular}

Diprediksi jumlah ikan asing di perairan Indonesia dan Aceh khususnya akan terus bertambah jika tidak ada perhatian yang serius dari pemerintah dan lembaga-lembaga terkait lainnya untuk membendung dan mengendalikan kegiatan introduksi ini.

Negara-negara yang mengintroduksi spesies ikan asing umumnya adalah negaranegara yang miskin keragaman jenis ikan yang potensial untuk budidaya, sehingga perlu mendatangkan jenis baru dalam kaitan untuk meningkatkan produksi perikanannya. Kebijakan ini dipandang keliru bagi Indonesia khususnya Aceh yang memiliki potensi keragaman jenis ikan ekonomis tinggi yang tergolong sangat banyak.

\section{STUDI KASUS INTRODUKSI SPECIES IKAN DI DANAU LAUT TAWAR}

Danau Laut Tawar merupakan danau terluas di Aceh. Danau ini terletak pada ketinggilan lebih dari $1.200 \mathrm{~m}$ dari permukaan laut, mempunyai luas lebih kurang 5.600 $\mathrm{Ha}$, dalaman rata-rata $35 \mathrm{~m}$ dan kedalaman maksimum $115 \mathrm{~m}$. Lebih kurang 25 sungai kecil mengalir ke dalam danau dan hanya ada satu sungai sebagai outflow utama danau yaitu Sungai Peusangan. 
Danau Laut Tawar memiliki arti penting bagi masyarakat Gayo, etnis lokal yang mendiami dataran tinggi tersebut, danau ini merupakan sumber air bersih bagi masyarakat setempat, pertanian, industri dan perikanan. Menurut data statistik yang ada, pada Tahun 2009 sekurang-kurangnya 225 orang nelayan mengantungkan hidupnya dari hasil tangkapan ikan danau dan lebih kurang 150 orang lainnya menjadikan danau ini sebagai tempat pembudidayaan ikan (Bapeda Aceh Tengah, 2009).

Salah satu sumberdaya perikanan yang ada di Danau Laut Tawar adalah ikan depik (Rasbora tawarensis), ikan ini bersifat endemik dan tergolong ikan yang terancam punah (threatened species) dan diketegorikan sebagai Critical Endangered Species (IUCN, 1990; CBSG, 2003). Ikan depik merupakan target utama bagi sebagian besar (46\%) nelayan di Danau Laut Tawar, menunjukkan betapa pentingnya ikan depik bagi nelayan dan masyarakat setempat. Namun sayangnya, produksi ikan dari Danau Laut Tawar terus menurun dari tahun ke tahun. Berdasarkan data statistik, penurunan produksi ikan Danau Laut Tawar mencapai 83,5\% selama dua dekade terakhir, sebagai ilustrasi pada tahun 1988 produksi ikan dari Aceh sebanyak 455 ton (DKP Aceh, 1989), menurun menjadi hanya 74,5 ton pada tahun 2008 (Bapeda Aceh Tengah, 2009). Fenomena yang sama juga terjadi pada ikan depik, hasil penelitian kami baru-baru ini menunjukkan bahwa hasil tangkapan (CPUE) ikan depik turun drastis $98.3 \%$ selama kurun waktu tiga dekade terakhir (Muchlisin et al., 2011).

Hasil wawancara dengan para nelayan diperoleh informasi bahwa pada kurun 1970an sampai 1980 an sebagian besar nelayan hanya mengunakan alat penangkapan tradisional berupa penyangkulan dan dedeseun, kedua alat ini hanya beroperasi pada musim penghujan saja, dan hanya beberapa orang nelayan yang memiliki modal besar saja yang memiliki jaring. Pada awal 1990an situasi ini mulai berubah sejak mulai diperkenalkannya jaring insang buatan pabrik dengan harga murah, dapat dibeli oleh siapa saja dan sangat mudah memperolehnya. Akibatnya adalah hampir semua nelayan beralih ke jaring insang bahkan dengan ukuran mata jaring kecil $(14 \mathrm{~cm})$, dan depik ditangkap sepanjang tahun dan mengakibatkan terjadinya kelebihan tangkap (over fishing). Bahkan saat ini boleh dikatakan tidak ada lagi alat tangkap penyakulan dan ada beberapa dedeseun yang masih aktif dimusin kemarau karena jumlah ikan yang bermigrasi ke sungai-sungai kecil semakin berkurang dan jarang terjadi.

Beberapa nelayan juga telah beralih ke usaha budidaya, hal ini menyebabkan jumlah keramba jaring apung meningkat tajam dalam kurun waktu 2 tahun terakhir, sebagai contoh terdapat 16 keramba apung pada Tahun 2006, meningkat menjadi 143 keramba pada Tahun 2008 (Bappeda Aceh Tengah, 2009). Sayangnya, sebagian besar ikan peliharaan adalah ikan hasil introduksi dari luar Aceh dan bahkan luar Indonesia, misalnya ikan nila (O. niloticus). Selain itu pula pengembangan kapasitas nelayan dinilai juga masih kurang, sehingga belum dapat menerapkan teknik budidaya ikan yang baik dan ramah lingkungan.

Pengembangan usaha budidaya ikan dengan intensitas pemberian pakan buatan yang tinggi tanpa diiringi dengan manejemen kualitas air yang baik akan berdampak buruk pada kondisi air danau dan seterusnya memberi dampak negatif terhadap populasi ikan di danau. Secara teoritis, hanya $10 \%$ dari total luas danau dapat dimanfaatkan untuk kegiatan budidaya yang bersifat ramah lingkungan. Selain mempertimbangkan luasan, lokasi penempatan juga penting diperhatikan agar limbah dari kegiatan budidaya ini tidak mencemari sumber air danau. Oleh karena itu kajian kelayakan usaha secara ekologis dan ekonomis penting dilakukan sebelum izin usaha diberikan. Sejauh ini pengusaha pembudidayakan ikan di Aceh belum semua memiliki izin usaha, apalagi memiliki hasil studi mengenai analisa dampak lingkungan (amdal) sebelum usaha dijalankan. Oleh karena itu Pemerintah Daerah setempat perlu benar-benar pro aktif dan selektif dalam pemberian izin usaha baik usaha perikanan maupun usaha- 
usaha lainnya yang berdampak langsung dan tidak langsung terhadap danau, misalnya hotel, restoran dan resort atau cottage.

Pemerintah Daerah Aceh Tengah telah menerbitkan PERDA No. 5 Tahun 1999 tentang pengelolaan sumberdaya perikanan, sayangnya implementasi dari PERDA ini masih sangat lemah dan bahkan pada beberapa poin perlu direvisi, misalnya aturan penggunaaan mata jaring minimal $1,5 \mathrm{~cm}$ dinilai sudah tidak sesuai dan perlu ditinjau ulang.

Selain disebabkan oleh faktor kerusakan lingkungan dan pencemaran danau, kehadiran spesies ikan asing di danau diduga juga sebagai penyebab menurunnya populasi ikan-ikan asli danau khususnya ikan depik. Hasil penelitian kami beberapa waktu lalu mendapati sekurangkurang ada tujuh species ikan asing yang diintroduksi baik secara sengaja maupun tidak ke DLT. Species-species tersebut adalah Clarias gariepinus (lele dumbo), Cyprinus carpio (ikan mas), Oreochromis mossambicus (mujair), O. niloticus (nila), plati pedang atau buntok (Xiphophorus helleri) dan, grass carp atau bawal (Ctenopharyngodon idella). Ikan sapu kaca (Hiposarcus pardalis) dilaporkan oleh neyalan juga telah ada di danau ini (Muchlisin, 2010). Bahkan pada tahun 2009 pemerintah setempat bekerjasama dengan Dinas Perikanan dan Kelautan Tk I melakukan introduksi ikan bandeng (Chanos chanos) ke DLT. Laporan terakhir yang kami terima bahwa di DLT juga sudah ditemukan ikan patin atau jambal (Pangasius) yang sebelumnya belum pernah ditemukan.

Ironisnya lagi program "restocking" telah disalah artikan oleh sebagian masyarakat bahkan pemerintah, kegiatan tabur benih ikan nila atau ikan mas ke Aceh misalnya telah menjadi kegiatan seremonial rutin pemerintah setempat, yang patut disayangkan kegiatan ini disponsori oleh lembaga yang sepatutnya menjaga kelestarian danau. Menurut data yang ada, lebih dari 725.000 ekor ikan asing telah diintroduksi ke Aceh selama kurun waktu 7 tahun terakhir (Tabel 3). Ikan-ikan ini sebagian telah membiak dan bahkan ada yang telah mendominasi populasi ikan di DLT, yaitu ikan nila (O. niloticus).

Tabel 3. Jenis dan Jumlah Ikan Asing yang Telah Diintroduksi ke Aceh.

Table 3. Total Introduction of Exotic Fish Species Into Lake Laut Tawar during 2003 to 2010.

\begin{tabular}{|c|c|c|c|c|c|c|c|c|c|}
\hline \multirow{2}{*}{ No } & \multirow{2}{*}{$\begin{array}{c}\text { Spesies/ } \\
\text { Species }\end{array}$} & \multicolumn{8}{|c|}{ Year } \\
\hline & & 2003 & 2004 & 2005 & 2006 & 2007 & 2008 & 2009 & 2010 \\
\hline 1 & $\begin{array}{l}\text { Nila/Tilapia, } \\
\text { Oreochromis } \\
\text { niloticus }\end{array}$ & 100,000 & 40,000 & 50,000 & 50,000 & 50,000 & 170,000 & - & 20,000 \\
\hline 2 & $\begin{array}{l}\text { Mas/ } \\
\text { Common } \\
\text { carp, } \\
\text { Cyprinus } \\
\text { carpio }\end{array}$ & 100,000 & 10,000 & - & - & 20,000 & - & 50,000 & 30,000 \\
\hline 3 & $\begin{array}{l}\text { Bandeng/ } \\
\text { Milk fish, } \\
\text { Chanos } \\
\text { chanos }\end{array}$ & - & - & - & - & - & - & 35,000 & \\
\hline 4 & $\begin{array}{l}\text { Ikan Cina/ } \\
\text { Grass carp, } \\
\text { Ctenophary- } \\
\text { ngodon idella }\end{array}$ & \multicolumn{8}{|c|}{$\begin{array}{l}\text { Diintroduksi sekitar tahun 1990an, namun tidak ada catatan berapa jumlah yang } \\
\text { ditebar. Menurut literatur yang ada, ikan ini tidak dapat membiak pada iklim } \\
\text { tropis seperti Indonesia/ Probably the fish has been introduced in 1990an, but } \\
\text { no information about how many individual have been introduced. According to } \\
\text { reference, this fish can not spawn in tropical region includes Indonesia }\end{array}$} \\
\hline Total & & 200,000 & 50,000 & 50,000 & 50,000 & 70,000 & 170,000 & 85,000 & 50,000 \\
\hline
\end{tabular}

Sumber: BBI Toweran dan Media Masa Lokal.

Source: Toweran hatchery, Aceh Tengah District. 
Hakikinya pengertian restocking adalah tabur ulang benih ikan yang memang telah ada secara alami disana, namun populasinya semakin berkurang. Oleh karena itu untuk mendukung program restocking ini perlu dilakukan kegiatan lain misalnya koleksi dan domestikasi induk-induk, selanjutnya dilakukan pemijahan secara buatan ataupun semi-alami, benih yang dihasilkan di restocking atau dilepaskan kembali ke alam dengan tujuan agar populasinya kembali normal dan seimbang, dan atau benih tersebut dapat digunakan juga untuk tujuan budidaya. Untuk tujuan ini, kajian biologi reproduksi perlu dilakukan sebelum dipijahkan dan jika larva-larva yang dihasilkan ingin digunakan untuk tujuan budidaya secara luas, aspek kebiasaan makan perlu dikaji agar dapat disiapkan pakan yang sesuai untuk species berkenaaan. Oleh karena itu kegiatan restocking ini bukanlah kegiatan yang berdiri sendiri akan tetapi merupakan hasil dari penelitian yang terpadu.

Pada kasus di Danau laut Tawar, kegiatan penebaran ikan yang dilakukan sampai saat ini bukanlah restocking akan tetapi lebih menjurus kepada introducing dan reintroducing (introduksi berulang) spesies asing ke danau, yang mengancam keberadaan spesies lokal misalnya depik, ikan yang bersifat endemik di Aceh.

Selain itu penggunaan dedeseun trap oleh beberapa nelayan di sungai-sungai kecil yang dijadikan oleh ikan depik tempat pemijahnya juga turut menyumbang kepada semakin menurunnya populasi ikan depik di Aceh. Dedeseun trap ini dengan sangat efektif menangkap ribuan induk-induk ikan depik setiap hari terutama pada puncak musim pemijahannya pada musim penghujan (Juli sampai Desember).

Fenomena-fenomena yang dipaparkan diatas sudah mulai terjadi di Aceh, nelayan setempat mengklaim bahwa saat ini populasi ikan depik dan kawan semakin menurun, namun sebaliknya populasi ikan nila semakin dominan. Dikhawatirkan populasi ikan depik akan semakin berkurang dan bahkan terancam punah.

\section{PENUTUP}

Disamping memperkuat perikanan tangkap perairan umum dengan restocking ikan-ikan asli setempat yang bernilai ekonomis tinggi. Pembangunan perikanan Aceh di masa depan perlu lebih ditumpukan pada perikanan budidaya, dan hal ini perlu dilakukan secara selaras antara perikanan budiadaya air tawar, payau dan laut. Dalam pengembangannya, perikanan budidaya (khususnya air tawar) Aceh dimasa depan harus juga memberdayakan ikan-ikan asli setempat yang memiliki nilai ekonomis tinggi, misalnya jenis-jenis keureling (Tor spp, ada 3 jenis ikan ini di perairan Aceh), lele lokal (Clarias spp, ada 3 jenis juga di Aceh), dan ikan gabus (Channa striata). Namun pengembangan budidaya harus dilakukan secara multi species (diversifikasi) dan tidak hanya bergantung pada satu atau dua species aja. Selain itu, pemilihan spesies yang bersifat herbivora perlu diberikan keutamaan untuk mengindari ketergantungan pada tepung ikan sebagai bahan baku utama makanan ikan yang sumber-sumbernya terus menurun seiring dengan penurunan hasil tangkapan ikan secara global.

Penelitian-penelitian awal tentang biologi dan ekologi ikan perlu dilakukan dan dilanjutkan dengan penelitian-penelitian yang menghasilkan teknologi tepat guna, misalnya teknologi pembenihan, makanan, pengelolaan kualitas air dan penyakit. Oleh karena itu kerjasama antara pihak-pihak terkait khususnya pemerintah dan perguruan tinggi perlu dilakukan dan diperkuat jika sudah ada.

Introduksi spesies ikan asing ibarat "buah simalakama" di satu pihak diperlukan, namaun dipihak lain dapat merugikan ikan-ikan lokal jika tidak dilakukan secara bertanggung jawab. Saat ini Pemerintah Aceh termasuk pemerintah di kabupaten/kota belum memiliki regulasi yang mengatur tentang introduksi spesies ikan asing ke perairan Aceh, dengan kondisi ini keberadaan spesies ikan lokal berada dalam ancaman serius. Oleh karena itu, introduksi species ikan asing perlu dihentikan serta merta, sebelum regulasi yang mengaturnya dibuat dan diterapkan, dipenyebaran dan 
perkembangan species asing yang telah ada pun perlu dimonitor dan dibatasi. Untuk itu diperlukan adanya kebijakan (aturan) yang mengatur introduksi ikan asing ke perairan Aceh.

Namun demikian, pada keadaan tertentu atau memaksa budidaya ikan asing yang sudah terlanjur masuk mungkin masih dapat dipertimbangkan dengan selektif, misalnya dapat dilakukan di kolam-kolam yang terkontrol bukan di perairan umum dengan menerapkan teknologi benih tunggal kelamin (mono sex) ataupun rekayasa genetika triploidi dan ginogenesis misalnya, untuk menghasilkan benih infertil (mandul), untuk itu kapasitas nelayan dan teknologi budidaya perlu ditingkatkan, namun tetap perlu dilakukan secara hati-hati dan dengan pengawasan yang ketat berlandaskan pada kajian-kajian ilmiah.

Secara ekonomi beberapa spesies lokal (misalnya Genus Tor) memiliki nilai ekonomi yang jauh lebih tinggi dibandingkan dengan spesies introduksi (misalnya nila atau lele dumbo), namun karena belum ada teknologi pemuliaan menyebabkan ikan-ikan ini belum dapat dibudidayakan secara massal. Oleh karena itu, Pemerintah Aceh khususnya perlu menetapkan prioritas spesies unggulan untuk dikembangkan baik untuk perikanan tangkap maupun perikanan budidaya. Untuk itu sebagimana yang telah diutarakan diatas, kajian-kajian awal terhadap spesies berkenaan perlu dilakukan, sebelum dikembangkan sebagai spesies unggulan. Semua langkahlangkah strategis yang diusulkan tersebut perlu mendapat payung hukum berupa Qanun (PERDA) dengan mempertimbangkan kearifan lokal yang telah ada dan dianut oleh masyarakat Aceh khususnya. Untuk tujuan tersebut perlu adanya kerjasama yang senerji antara lembaga pemerintah (eksekutif), legislatif dan perguruan tinggi untuk melakukan kajian-kajian bersama dalam membangun database.

Khusus untuk kasus di Danau Laut Tawar, penetapan kawasan reservat di Danau Laut Tawar perlu dilakukan segera, penetapan aturan larangan tangkap terhadap ikan depik mengikut masa, tempat dan ukuran ikan yang boleh ditangkap juga perlu diambilkira dan ketetapan pengunaan ukuran mata jaring yang telah ada juga perlu dikaji ulang dan diterapkan secara konsisten. Hasil penelitian kami menunjukkan bahwa ikan depik memijah tiga kali dalam setahun, yaitu pada Maret, September dan Desember dengan puncaknya pada September (Muchlisin et al., 2010), oleh karena itu larangan penangkapan sebaiknya dilakukan pada masa-masa pemijahan tersebut. Kami juga telah mengidentifikasi beberapa lokasi tempat pemijahan ikan ini di beberapa sungai kecil yang mengalir ke danau (Muchlisin, 2011), oleh karena itu lokasi-lokasi ini mungkin dapat dipertimbangkan sebagai kawasan reservat. Penggunaan dedeseun trap untuk menangkap induk-induk ikan yang akan bertelur disungai-sungai kecil di sekeliling danau juga perlu dilarang.

Kearifan lokal atau hukum adat dalam pemanfaatan sumberdaya ikan di PUD yang telah ada di beberapa daerah, misalnya di beberapa tempat di Aceh Selatan, perlu digalakkan dan disokong oleh pemerintah dan jika perlu ditingkatkan untuk menjadi hukum formal (qanun). Hukum adat ini telah tebukti lebih efektif, karena keterlibatan masyarakat secara aktif dalam penyusunan, pelaksanaan dan pengawasannya.

\section{DAFTAR PUSTAKA}

Alcaraz, C and E. Garcia-Berthou. 2007. Food of an endangered cyprinodont (Aphanius iberus): ontogenetic diet shift and prey electivity. Environmental Biology of Fishes, 78: 193-207.

Ali, A. 2000.Status Perikanan dan sumber alam akuatik di Malaysia. School of Biological Sciences, University Science Malaysia, Penang, Malaysia.

Almodovar, A., G.G. Nicola, B. Elvira and J.L. Garcia-Marin. 2006. Introgression variability among Iberian brown trout Evolutionary Significant Units: the influence of local management and environmental features. Freshwater Biology, 51: 1175-1187. 
Bappeda Provinsi Aceh. 2008. Geografi pemerintah Aceh. Badan Perencanaan Pembangunan Daerah, Provinsi NAD, Banda Aceh.

Bappeda Aceh Tengah. 2009. Aceh Tengah dalam angka. Badan Perencanaan Pembangunan Kabupaten Aceh Tengah, Takengon.

Barlow, C.G and A. Lisle. 1987. Biology of the nile perch Lates niloticus (Pisces: Centropomidae) with reference to its proposed role as a sport fish in Australia. Biological Conservation, 39: 269-289.

Casal, C.M.V. 2006. Global documentation of fish introductions: the growing crisis and recommendations for action. Biological Invasions, 8: 3-11.

CBSG. 2003. Conservation Assessment and Management Plan for Sumatran Threatened Species: Final Report. IUCN SSC Conservation Breeding Specialist Group, Apple Valley, MN, USA.

Chong, V.C., P.K.Y. Lee and C.M. Lau. 2010. Diversity, extinction risk and conservation of Malaysian fishes. Journal of Fish Biology, 76: 2009-2066.

DKP Aceh 1989. Perikanan dalam angka. Laporan Tahunan Dinas Perikanan Provinsi D.I. Aceh, Tahun 1988, Banda Aceh.

FAO. 2005. International mechanism for the control and responsible use of alien species in aquatic ecosystem. Report of an ad hoc expert consultation 27-30 August 2003, Xishuangbanna, People's Republic of China.

GISP. 2004. 100 of the world's worst invasive alien species. http://www.issg.org/booklet. pdf. November 29, 2008.

Gurung, T.B. 2005. Responsible introduction of alien fish \& biodiversity in Nepal. http:// www.enaca.org/modules/news/article. php?storyid=579.

Islam, M.M., A.S.M.R. Amin and S.K. Sarker. 2003. Invasive Alien Species in Bangladesh. In: N. Pallewatta, J.K. Rease and A.T. Guiterrez (eds). Invasive Alien Species in South-
Southeast Asia, National Reports and Directory of Resources. The Global Invasive Species Program, Dhaka, Bangladesh.

IUCN. 1990. IUCN red list of threatened animal. IUCN, Gland and Cambridge.

Kumar, A.B. 2000. Exotic fishes and freshwater fish diversity. Zoos' Print Journal, 15(11): 363-367.

Muchlisin, Z.A and M.N. Siti Azizah. 2009. Diversity and distribution of freshwater fishes in Aceh waters, northern Sumatera, Indonesia. International Journal of Zoological Research, 5(2): 62-79.

Muchlisin, Z.A. 2010. Biodiversity of freshwater fishes in Aceh Indonesia with emphasis study on the biogeography of depik (Rasbora tawarensis) an endemic and threatened fish in Lake Laut Tawar. Ph.D thesis Universiti Sains Malaysia.

Muchlisin, Z.A., M. Musman and M.N. Siti Azizah. 2010. Spawning seasons of Rasbora tawarensis in Lake Laut Tawar, Aceh Province, Indonesia. Reproductive Biology and Endocrinology, 8:49 (2010).

Muchlisin, Z.A., N. Fadli, E. Rudi, T. Mendo and M.N. Siti Azizah. 2011. Estimation of production trend of the depik, Rasbora tawarensis (Teleostei, Cyprinidae), in Lake Laut Tawar, Indonesia. AACL Bioflux, 4(5): 590-597.

Muchlisin, Z.A. 2011. Spawning grounds of depik, Rasbora tawarensis (Teleostei, Cyprinidae) in Lake Laut Tawar, Indonesia. Proceedings of Annual International Conference Syiah Kuala University, Banda Aceh 29-30 November 2011. pp 95-99.

Nicola, G.G., Almodovar, A. and Elvira, B. 1996. The diet of introduced largemouth bass, Micropterus salmoides, in the Natural Park of the Ruidera Lakes, central Spain. Polskie Archiwum Hydrobiologii, 43: 179-184.

Nowak, M., P. Szczerbik, K. Tatoj and W. Popek. 2008. Non-native freshwater fishes in Poland: an overview. AACL Bioflux, 1(2): 173-191. 
Rabitsch, W. and F. Essl. 2006. Biological invasions in Austria: patterns and case studies. Biological Invasions, 8: 295-308.

Saunders, D. L., J.J. Meeuwig and C. J. Vincent. 2002. Freshwater protected area: strategies for conservation. Conservation Biology, 16:30-41.

Ribeiro, F., B. Elvira, M.J. Collares-Pereira and P.B. Moyle. 2008. Life-history traits of nonnative fishes in Iberian watersheds across several invasion stages: a first approach. Biological Invasions, 10: 89-102.

Roll, U., T. Dayan, D. Simberloff and M. Goren. 2007. Characteristics of the introduced fish fauna of Israel. Biological Invasions, 9: 813-824.

Seehausen, O., F. Witten, E.F. Katunzi, J. Smits and N. Bouton. 1997. Pattern of the remnant cichlid fauna in southern lake Victoria. Conservation Biology, 11: 890-904.

Sorensen, P.W. and T. R. Hoye. 2007. A critical review of the discovery and application of a migratory pheromone in an invasive fish, the sea lamprey Petromyzon marinus L. Journal of Fish Biology, 71: 100-114.
Strecker, U. 2006. The impact of invasive fish on an endemic Cyprinodon species flock (Teleostei) from Laguna Chichancanab, Yucatan, Mexico. Ecology of Freshwater Fish, 15: 408-418.

Tan, B.C. and T. Koh-Siang. 2003. Invasive Alien Species in Singapore. In: N. Pallewatta, J.K. Rease and A.T. Guiterrez (eds). Invasive Alien Species in South-Southeast Asia, National Reports and Directory of Resources. The Global Invasive Species Program. pp. 85-90.

Wargasasmita, S. 2002. Ikan air tawar Sumatera yang terancam punah. Jurnal Iktiologi Indonesia, 2 (2):41-49.

Zaidy, A.B. 2001. Budidaya Laut : Suatu upaya mengurangi ketergantungan dari perikanan tangkap. Makalah Falsafah Sains, Program Pasca Sarjana, Institute Pertanian Bogor, Bogor, Indonesia.

Zenetos, A., M. Panucucci-Papadopoulou, S. Zogaris, E. Papastergiadou, L. Vardakas, K. Aligiza and A. N. Economou. 2009. Aquatic alien species in Greece (2009): tracking sources, patterns and effects on the ecosystem. Journal of Biological Research-Thessaloniki, 12: 135- 172. 